\title{
Personality differences amongst drag racers and archers: implications for sport injury rehabilitation
}

\author{
Rhonda Cohen ${ }^{1 *}$, Bahman Baluch², Linda J. Duffy ${ }^{2}$ \\ 'The London Sport Institute, London, UK \\ ${ }^{2}$ School of Science and Technology, Middlesex University, London, UK
}

Personality trait of an athlete is a significant factor in sports injury rehabilitation. The aim of the present study is to investigate whether there are differences in personality traits between male and female, professional and amateur athletes from sports representing two ends of extreme to traditional namely; drag racing and archery. Overall 189 male and female, professional and amateur drag racers $(n=144)$ and archers $(n=45)$ took part in this study. Participants completed the personality traits of extroversion and neuroticism as measured by Eysenck's classic Personality Inventory dimensions and thrill and adventure seeking (TAS), experience seeking (ES), disinhibition (DIS), boredom susceptibility (BS), and sensation seeking (SS) as measured by Zuckerman's Sensation Seeking Scale. The results showed that professionals scored significantly lower on neuroticism compared to amateurs. Drag racers scored significantly higher on TAS, DIS, and SS compared to archers and there were gender differences amongst archers on TAS and SS with males scoring higher than females. Such differences in personality factors and the readiness to take risks, lack of caution, and adventurous spirit can influence the risk of injury in athletes and indeed may influence the outcome of rehabilitation. Practitioners would need to recognise difference in personality traits associated with the type of sport and the choice of interventions strategies.

Keywords: Drag racing, Archery, Personality, Rehabilitation, Injury

\section{INTRODUCTION}

\section{Sport injury, personality, and rehabilitation}

There is now a realisation that risk of injury in sport differs according to the type and nature of sporting activity (Laver et al., 2017). Sports differ on a continuum ranging from extreme to traditional (Cohen et al., 2018; Immonen et al., 2018). Extreme sports, for example drag racing, in comparison to those considered as traditional, for example Archery, are defined as a competitive (comparison or self-evaluative) activity within which the participant is subjected to natural or unusual physical and mental challenges such as speed height, depth, or natural forces and where fast and accurate cognitive perceptual processing may be required for a successful outcome. An unsuccessful outcome is more likely to result in the injury or even fatality of the participant in extreme sport (Laver et al., 2017). However, equally prominent is the per-

sonality characteristic of the athlete that may be considered a factor not only in increased risk of injury but also as a factor in sport rehabilitation. "People with particular personality characteristics deliberately seek out situations where they can experience high arousal in the form of pleasant feelings of excitement" (Pain and Kerr, 2004). The realization that particular personality traits may be a contributing factor in sport injury has led researchers to take notice of psychological factors in relation to personality traits in their models of sport injury rehabilitation (Schwab-Reese et al., 2012). Personality traits are considered to affect not only the process of rehabilitation but also the predicted outcome (Pain and Kerr, 2004; Slimani et al., 2018). For example, those that engage in high risk sports exhibit particular personality characteristics, such as high on sensation seeking (SS). SS as defined by Zuckerman (1990) is the need for varied, novel, and complex sensations and experiences and the willingness to take physical, social, legal,

*Corresponding author: Bahman Baluch (D) https://orcid.org/0000-0003-0650-4421

School of Science and Technology, Middlesex University, London, UK

Tel: +442084115000, Fax: +444115343, E-mail: b.baluch@mdx.ac.uk

Received: July 26, 2018 / Accepted: August 29, 2018

This is an Open Access article distributed under the terms of the Creative Commons Attribution Non-Commercial License (http://creativecommons.org/licenses/by-nc/4.0/) which permits unrestricted non-commercial use, distribution, and reproduction in any medium, provided the original work is properly cited. 
and financial risks for the sake of such experiences. Those with this aspect of personality may in some way exhibit active coping strategies during rehabilitation (Meredith et al., 2015). At the same time they may be more likely to ignore medical advice and continue with potentially destructive behaviour post rehabilitation (e.g., Pain and Kerr, 2004). Such consideration may raise the key question of what is the relationship between personality traits and sport performance? And whether there are differences in personality traits between those representing extreme and traditional sports? Moreover, are factors such as level of expertise (professional vs. amateur) and gender a contributing factor?

\section{Personality and sport performance}

Over the past years there has been a growing body of research examining the relationship between personality traits and sporting performance (Eysenck et al., 1982; Rhodes and Smith, 2006). Studies in personality and sport have focused on various aspects. For example, personality profiling in sport has been shown to be beneficial for transitioning individuals from youth teams to adult teams (Allen and Laborder, 2014) as well as benefitting established athletes (Bauger et al., 2013). In addition, links between personality and long-term athletic success was evidenced by Allen et al. (2013) and Anshel and Lidor (2014). However, an area that is under researched is extreme sport and limited considerations have been taken into account on two significant factors namely; gender and level of skill in the format of professional versus amateur. Research using both Eysenck's Personality Inventory (EPI) (Eysenck et al., 1985) and Zuckerman's (2004) Sensation Seeking Scale (SSS-V) has shown that those who engage in a variety of sports (high to low risk) are more extrovert and score higher on SS than those involved in low risk sport or when compared to nonsporting participants (Zuckerman, 2004). However, there is also evidence that alternative variables namely gender (Eagleton et al., 2007), age (Butković and Bratko, 2003), and level of skill (Duffy et al., 2004; Watson and Pulford, 2004) may also be important factors in determining the personality typology of specific athletes (Cleary and Zimmerman, 2001; Garland and Barry, 1991).

In relation to gender differences, it is well known that significant gender differences in personality trait scores exist (Chapman et al., 2007; VanZile-Tamsen et al., 2006). Moreover, research on risk taking also reveals a clear gender divide whereby males engage more often in risk taking behaviour than females (Harris and Jenkins, 2006). Reliable research on 'extreme sport' reveals differences between men and women in decision making related to engagement in risky behaviours (Larkin and Pines, 2003). Moreover, underlying personality characteristics are likely to influence this type of risk taking behaviour amongst women (Cooper et al., 2003).

Another factor is the age of the athlete and risk taking behaviour. For example, Ruedl et al. (2015) has shown that young adults have higher involvement in risk taking behaviour than older adults and score higher on SS than older adults (Martin et al., 2002). Similarly there is a decrease in SS with increasing age (Butković and Bratko, 2003). Level of skill, namely the professional versus amateur (or expert versus novice) distinction have also been taken into account when studying the relationship between sport and personality (Eysenck et al., 1982).

Egloff and Gruhn (1996) argued that there is a need to further examine the extent to which in sports those classified as professional compared to those considered as amateur differ in their personality traits. Particularly taking into account sports differing from extreme to traditional. Personality traits namely; Extroversion and neuroticism and SS measures show strong correlations with sport (Cleary and Zimmerman, 2001; Eysenck et al., 1982) although studies on this subject are still limited (Goma-i-Freixanet et al., 2012). Moreover there is a dearth of empirical research investigating personality traits on comparisons of 'extreme sports' and nonextreme traditional sports (Zuckerman, 2007). According to Goma-i-Freixanet et al. (2012), from 1974 to 2001, only two studies have aimed at comparing 'extreme sports' to medium risk sports: i.e., rugby to marathon running (Potgieter and Bisschoff, 1990) and karate to tennis (Chirivella and Martínez, 1994). Thus whether specific groups of sports may predict variations in personality is a topic that requires further investigation (Schneider et al., 2007).

\section{Aims of the present study}

The main aim of the present study is to investigate whether there are differences in personality traits as measured by EPI dimensions and SSS-V when comparing men and women in two categories of professional and amateur participating in 'extreme sport' (drag racers) and traditional sport (archery). The two sports selected for this investigation could be viewed as an appropriate benchmark in terms of sporting activity, injuries and its relationship to personality traits. Drag racing, as argued previously, is an example of extreme sport, archery is seen as a traditional, nonextreme sport, particularly in terms of SS and injuries. Furthermore, both archery and drag racing are individual sports with men and women competing against each other on equal terms, thus lending itself to the examination of gender differences. Any changes in 
scores between participants engaged in opposite ends of the sporting continuum would be a more accurate reflection of any relationship between personality traits and sporting behaviour. Specific questions investigated are whether there are significant differences between male and female, professional and amateur drag racers and archers on extroversion and neuroticism as measured by EPI and thrill and adventure seeking (TAS), experience seeking (ES), disinhibition (DIS), boredom susceptibility (BS), and SS as measured by SSS-V.

\section{MATERIALS AND METHODS}

\section{Populations and sample size}

In total 189 male and female, professional and amateur drag racers and archers took part in this study. Drag racers $(n=144)$, 108 males (mean age, 31.49; standard deviation [SD], 12.7) and 36 females (mean age, 29.88; SD, 10.73) and archers $(\mathrm{n}=45), 30$ males (mean age, 36; SD, 11.93) and 15 females (mean age, 38.2; $\mathrm{SD}, 11.81)$.

\section{Materials}

Two questionnaires were used in the present study, EPI (Eysenck and Eysenck, 1978; Eysenck et al., 1982) and SSS-V (Zuckerman, 2007). EPI measures extraversion (24 items) and neuroticism (24 items). It is a forced-answer questionnaire, which requires a yes or no to each question. The internal consistency and test retest reliability for extraversion and neuroticism, according to (Eysenck and Eysenck, 1978; Eysenck et al., 1982) range from 0.75-0.90. According to Bullock and Gilliland (1993) EPI is more preferred than Eysenck's Personality Questionnaire (EPQ) as it also measures impulsivity. Both the EPI/EPQ are more frequently used in measuring sport personality than the neuroticism, extroversion, openness (big five personality traits [openness to experience, conscientiousness, extraversion, agreeableness, and neuroticism] which have not been used as frequently in research) (Allen et al., 2013).

The SSS-V is a valid and reliable method for identifying an individual's behavioural expression of SS traits (Zuckerman, 2007; Zuckerman et al., 1978). SS overall is defined as the seeking of varied, novel, and intense stimuli and the willingness to take risks for the sake of such experience (Zuckerman, 2004). The SSS-V was revised in collaboration with data from a large-scale study that Zuckerman carried out with Eysenck and Eysenck (1978) and is the test mostly used for measuring SS in high risk sports (Goma-i-Freixanet et al., 2012).

\section{Level of performance criteria}

Level of performance criteria (professional vs. amateur) for selection as participants for the two sports in the present study was as follows:

(a) Drag racers (extreme sport) - For this group of participants the international governing body of motorsports (Federation Internationale de L'Automobile) classifications was used to make a distinction between professional and amateur drag racers. On that basis professional drag racers were classified as those who were licensed extreme sport drivers who receive monetary rewards when placed in the top three of an event and compete in the professional classes. Those competing in professional classes include those who compete in categories of cars such as top fuel, top methanol dragster, funny car, and pro stock. Those drag racers classified as amateurs compete in other categories such as comp, super stock, and stock.

(b) Archers (traditional sport) - For this group of participants those who compete at either international or national level were classified as professional. Those club members who played regularly in competitions but were not in the professional category were classified as amateur.

\section{Procedure}

Ethical approval for this research was granted by Middlesex University Ethics Committee (approval number: AYL00009MST) and all codes of ethics were adhered to throughout the research. Both questionnaires used in the present study namely; the EPI and SSS-V were available online through Survey Monkey or in hard copy. Drag racers were recruited through the Eurodragster website and face to face at race meetings, whereas archers were recruited through archery clubs and archery websites. All archery tests were completed either in a quiet area within a club or via survey Monkey online. The EPI was handed out first, followed by the SSS-V.

Table 1. Extroversion and neuroticism as per gender, sport, and level of skill

\begin{tabular}{llllr}
\hline Sport & Gender & Skill & Extroversion & Neuroticism \\
\hline Drag racer & Male & Professional & $13.50 \pm 4.31$ & $10.50 \pm 5.23$ \\
Drag racer & Female & Professional & $14.00 \pm 5.09$ & $9.55 \pm 5.17$ \\
Drag racer & Male & Amateur & $13.55 \pm 4.39$ & $11.21 \pm 4.85$ \\
Drag racer & Female & Amateur & $11.96 \pm 3.58$ & $12.70 \pm 6.10$ \\
Archer & Male & Professional & $13.16 \pm 4.89$ & $8.66 \pm 5.43$ \\
Archer & Female & Professional & $11.50 \pm 1.29$ & $11.00 \pm 1.82$ \\
Archer & Male & Amateur & $11.61 \pm 3.48$ & $10.88 \pm 5.29$ \\
Archer & Female & Amateur & $12.45 \pm 4.01$ & $14.00 \pm 5.23$ \\
\hline
\end{tabular}

Values are presented as mean \pm standard deviation. 


\section{RESULTS}

Mean extroversion and neuroticism with corresponding standard deviations as per gender, sport and level of skill are shown in Table 1.

Two sports (drag racing, archery) by two Skills (professional, amateur) by two gender factorial analysis of variance (ANOVA) was conducted once on the extroversion and on the second run on the neuroticism, scores using age as a covariate.

\section{Extroversion}

There were no significant main effects for all the variables with $F(1,180)=0.89$, mean square error $(\mathrm{MSe})=15.64, P<0.34, \eta_{p}{ }^{2}=$ 0.005 for sport, $F(1,180)=1.05$, MSe $=18.53, P<0.3, \eta_{p}{ }^{2}=0.006$ for skill, $F(1,180)=0.3$, MSe $=5.29, P<0.58, \eta_{p}^{2}=0.002$ for gender. There were also no significant two- or three-way interactions with $F(1,180)=0.016$, MSe $=0.27, P<0.9, \eta_{p}^{2}=0.0001$ for sport by gender, $F(1,180)=0.266$, MSe $=4.65, P<0.6, \eta_{p}^{2}=0.001$ for sport by skill, $F(1,180)=0.05$, MSe $=0.91, P<0.82, \eta_{p}^{2}=0.0001$ for gender by skill and $F(1,180)=2.3, \mathrm{MSe}=40.28, P<0.13, \eta_{p}^{2}=$ 0.013 for three-way interaction of sport by gender by skill.

\section{Neuroticism}

There was a significant main effects for Skill with $F(1,180)=$ 4.27, MSe $=115.86, P<0.04, \eta_{p}^{2}=0.02$. All other main effects and two- and three-way interactions were found not to be significant with $F(1,180)=0.03$, MSe $=0.8, P<0.86, \eta_{p}^{2}=0.0001$ for sport, $F(1,180)=1.97$, MSe $=53.49, P<0.16, \eta_{p}^{2}=0.01$ for gender. There were also no significant two- or three-way interactions with $F(1,180)=1.32$, MSe $=36, P<0.25, \eta_{p}^{2}=0.007$ for sport by gender, $F(1,180)=0.11$, MSe $=3.01, P<0.73, \eta_{p}^{2}=0.001$ for sport by skill, $F(1,180)=0.58$, MSe $=15.82, P<0.44, \eta_{p}{ }^{2}=0.003$ for gender by skill and $F(1,180)=0.13$, MSe $=3.58, P<0.7, \eta_{p}^{2}=$ 0.001 for the three-way interaction of sport by gender by skill.

Mean TAS, ES, DIS, BS, and SS scores with corresponding standard deviations as per gender, sport and level of skill are shown in Table 2.

Two sport (drag racing, archery) by two skill (professional, amateur) by two gender factorial ANOVA was conducted on TAS, followed by ES, DIS, BS, and SS using age as a covariate.

\section{Thrill and adventure seeking}

There was a significant main effects for Sport with $F(1,180)=$ 4.86, MSe $=33.23, P<0.02, \eta_{p}{ }^{2}=0.02$. The other two main effects were found not to be significant with $F(1,180)=2.49$, MSe $=17.04$, $P<0.11, \eta_{p}^{2}=0.01$ for gender, $F(1,180)=1.99$, MSe $=13.63, P<$ $0.15, \eta_{p}^{2}=0.01$ for skill. There was a significant two-way interactions with $F(1,180)=3.88, \mathrm{MSe}=26.52, P<0.05, \eta_{p}^{2}=0.02$ for sport by gender. Analysis of simple effects showed a significant difference between male and female archers with $t(43)=2.3, P<$ 0.026 but not for drag racers with $t(142)=-0.59, P<0.55$. All other two- and three-way interactions were found not to be significant with $F(1,180)=0.22$, MSe $=1.5, P<0.63, \eta_{p}{ }^{2}=0.001$ for sport by skill, $F(1,180)=1$, MSe $=6.85, P<0.31, \eta_{p}^{2}=0.006$ for gender by skill and $F(1,180)=0.72$, MSe $=4.93, P<0.39, \eta_{p}^{2}=$ 0.004 for the three-way interaction of sport by gender by skill.

\section{Experience seeking}

There were no significant main effects for all the variables with $F(1,180)=0.68, \mathrm{MSe}=2.9, P<0.4, \eta_{p}^{2}=0.004$ for sport, $F(1$, $180)=1.82$, MSe $=7.71, P<0.17, \eta_{p}^{2}=0.01$ for gender, $F(1,180)=$ $0.04, \mathrm{MSe}=0.17, P<0.84, \eta_{p}{ }^{2}=0.0001$ for skill. There were also no significant two- or three-way interactions with $F(1,180)=$ 1.61, MSe $=6.81, P<0.2, \eta_{p}^{2}=0.009$ for sport by gender, $F(1$,

Table 2. TAS, ES, DIS, BS, and SS scores as per gender, sport, and level of skill

\begin{tabular}{|c|c|c|c|c|c|c|c|}
\hline Sport & Gender & Skill & TAS & ES & DIS & BS & SS \\
\hline Drag racer & Male & Professional & $6.90 \pm 2.48$ & $5.03 \pm 2.40$ & $5.71 \pm 2.26$ & $3.40 \pm 2.09$ & $21.37 \pm 6.09$ \\
\hline Drag racer & Female & Professional & $7.00 \pm 2.50$ & $5.22 \pm 2.68$ & $5.22 \pm 2.16$ & $4.44 \pm 2.29$ & $21.88 \pm 5.53$ \\
\hline Drag racer & Male & Amateur & $6.63 \pm 3.01$ & $5.36 \pm 1.99$ & $6.26 \pm 2.47$ & $4.00 \pm 2.44$ & $22.15 \pm 6.84$ \\
\hline Drag racer & Female & Amateur & $7.03 \pm 2.31$ & $5.11 \pm 1.73$ & $5.44 \pm 2.60$ & $3.29 \pm 2.10$ & $20.88 \pm 5.43$ \\
\hline Archer & Male & Professional & $7.16 \pm 3.24$ & $6.83 \pm 2.20$ & $5.25 \pm 2.41$ & $3.83 \pm 2.12$ & $23.08 \pm 8.05$ \\
\hline Archer & Female & Professional & $4.50 \pm 2.38$ & $4.50 \pm 1.00$ & $3.75 \pm 4.11$ & $2.75 \pm 2.06$ & $15.50 \pm 8.58$ \\
\hline Archer & Male & Amateur & $5.61 \pm 2.27$ & $5.33 \pm 1.84$ & $4.33 \pm 1.60$ & $3.27 \pm 1.74$ & $16.55 \pm 6.80$ \\
\hline Archer & Female & Amateur & $4.36 \pm 1.80$ & $5.45 \pm 1.80$ & $4.54 \pm 1.50$ & $3.54 \pm 1.50$ & $17.90 \pm 4.61$ \\
\hline
\end{tabular}

Values are presented as mean \pm standard deviation.

TAS, thrill and adventure seeking; ES, experience seeking; DIS, disinhibition; BS, boredom susceptibility; SS, sensation seeking. 
$180)=0.2, \mathrm{MSe}=0.86, P<0.65, \eta_{p}^{2}=0.001$ for sport by skill, $F(1,180)=1.42$, MSe $=6.02, P<0.23, \eta_{p}{ }^{2}=0.008$ for gender by skill and $F(1,180)=2.96$, MSe $=12.55, P<0.08, \eta_{p}{ }^{2}=0.01$ for three-way interaction of sport by gender by skill.

\section{Disinhibition}

There was a significant main effect for sport with $F(1,180)=$ 4.11, MSe $=22.08, P<0.04, \eta_{p}{ }^{2}=0.02$. All other main effects and two- and three-way interactions were found not to be significant with $F(1,180)=1.84$, MSe $=9.9, P<0.17, \eta_{p}^{2}=0.01$ for gender, $F(1,180)=0.01, \mathrm{MSe}=0.06, P \leq 0.91, \eta_{p}^{2}=0.0001$ for skill. There were also no significant two- or three-way interactions with $F(1$, 180) $=0.008, \mathrm{MSe}=0.04, P<0.92, \eta_{p}^{2}=0.0001$ for sport by gender, $F(1,180)=0.08, \mathrm{MSe}=0.44, P<0.77, \eta_{p}^{2}=0.0001$ for sport by skill, $F(1,180)=0.8$, MSe $=4.32, P<0.37, \eta_{p}^{2}=0.004$ for gender by skill and $F(1,180)=1.83, \mathrm{MSe}=9.82, P<0.17, \eta_{p}{ }^{2}=0.01$ for the three-way interaction of sport by gender by skill.

\section{Boredom susceptibility}

There were no significant main effects for all the variables with $F(1,180)=0.62, \mathrm{MSe}=3.02, P<0.43, \eta_{p}^{2}=0.003$ for sport, $F(1$, $180)=0.11, \mathrm{MSe}=0.53, P<0.74, \eta_{p}^{2}=0.001$ for skill, $F(1,180)=$ $0.06, \mathrm{MSe}=0.33, P<0.79, \eta_{p}^{2}=0.0001$ for gender. There were also no significant two- or three-way interactions with $F(1,180)=$ $0.37, \mathrm{MSe}=1.8, P<0.54, \eta_{p}{ }^{2}=0.002$ for sport by gender, $F(1$, $180)=0.25, \mathrm{MSe}=1.22, P<0.61, \eta_{p}^{2}=0.001$ for sport by skill, $F(1,180)=0.11, \mathrm{MSe}=0.11, P<0.87, \eta_{p}{ }^{2}=0.0001$ for gender by skill and $F(1,180)=3.2, \mathrm{MSe}=15.86, P<0.07, \eta_{p}{ }^{2}=0.01$, for three-way interaction of sport by gender by skill.

\section{Sensation seeking}

There was a significant main effects for Sport with $F(1,180)=$ 4.26, $\mathrm{MSe}=171.38, P<0.04, \eta_{p}^{2}=0.02$. The other two main effects were found not to be significant with $F(1,180)=1.77$, MSe $=$ $71.29, P<0.18, \eta_{p}^{2}=0.01$ for gender, $F(1,180)=1.62$, MSe $=65.25$, $P<0.2, \eta_{p}^{2}=0.009$ for skill. There were no significant two-way interactions with $F(1,180)=0.95, \mathrm{MSe}=38.36, P<0.33, \eta_{p}{ }^{2}=$ 0.005 for sport by gender, $F(1,180)=0.32, \mathrm{MSe}=13.08, P<0.56$, $\eta_{p}{ }^{2}=0.002$ for sport by skill and $F(1,180)=2.37, \mathrm{MSe}=95.58$, $P<0.12, \eta_{p}{ }^{2}=0.013 . F(1,180)=1, \mathrm{MSe}=6.85, P<0.31, \eta_{p}{ }^{2}=$ 0.006 for gender by skill. There was, however, a significant threeway interaction with $F(1,180)=5.48, \mathrm{MSe}=220.37, P<0.02$, $\eta_{p}^{2}=0.03$ for sport by gender by skill. Analysis of simple effects showed a significant difference between male and female archers with $t(43)=2.3, P<0.026$ but not for drag racers with $t(142)=$
$-0.59, P<0.55$.

\section{DISCUSSION}

Examining possible differences in personality traits between professional and amateur, males and females engaged in the extreme sport of drag racing compared to the traditional sport of archery was the main aim of the present study. The results generally showed that whilst there was no difference in extroversion scores between drag racers and archers, and for the level of skill or gender, the results of neuroticism showed that overall professionals scored significantly lower compared to amateurs. Drag racers scored significantly higher on TAS, DIS, and SS compared to archers and, there were gender differences amongst archers on TAS and SS with males scoring higher than females.

\section{Drag racers, archers, and Eysenck's personality traits}

The current study did not find any significant difference in extraversion between drag racers and Archers, even though according to Rhodes and Smith (2006) extraversion score is typically different between those who participate in various sports. For example, Kajtna et al. (2004) have shown that those who engage in extreme sport, i.e., an overall mixed cohort of high risk athletes, were higher in extraversion than traditional sports. Furthermore, in examining specific extreme sports, British bobsleighers were found to be higher in extraversion when compared to cyclists (Eysenck et al., 1982). This discrepancy in results thus further highlights the fact that extraversion as a personality trait may be sport specific and has to be investigated between various sports and within different categories of extreme versus traditional.

Another finding of the present study was that there was no gender differences on extroversion scores. Eysenck et al. (1982) considered gender as an important variable in relation to personality and extreme sport although this premise was not supported in the current research which found males and females to be similar in extraversion regardless of whether they play traditional or extreme sport. This, however, in part could be due to the relatively smaller number of females in comparison to the males in the present study. This, however, was unavoidable at the time of data collection due to the relatively fewer females taking part in drag racing or archery compared to males.

Eysenck et al. (1982) also points out that outstanding performers or 'professionals' would score higher on extraversion than amateur athletes, however, this was also not demonstrated in this study as there were no significant difference in extraversion score 
in relation to the level of skill, i.e., between professionals and amateurs. As studies on level of skill and personality traits and its relationship between professionals and amateurs are scarce, further research would be able to show if the present pattern of results indicates a universal trend or that it is specific to this study.

There was, however, a significant difference in neuroticism with regards to level of skill. According to the literature, neuroticism is predominantly lower in athletes, particularly professional athletes (Eysenck et al., 1982). The present study confirmed this claim with finding significant differences on neuroticism scores with regards to the level of skill between professionals and amateurs, with professionals scoring lower than amateurs. However, interesting to note is that whilst level of skill was found to be significant there was no main effect for type of sport namely; drag racing versus archery. Further research thus needs to examine participants from a variety of extreme and traditional sports in order to understand the uniqueness of the demands and competencies it places on its athletes and its possible relationship with personality traits, in particular neuroticism scale (Barlow et al., 2013; Guszkowska and Bołdak, 2010).

\section{Drag racers, archers, and SS traits}

Significant differences were found between participants on SS traits whereby drag racers scored significantly higher than archers on the overall SS scale, as well as the subscales of TAS and DIS. This supports previous research findings whereby high-risk sports athletes were highly correlated with the need for stimuli-SS (Guszkowska and Bołdak, 2010). Athletes low in SS predominantly avoid taking risks whilst extreme sport athletes have a higher need for SS (Jack and Ronan, 1998; Kerr, 1991; Rossi and Cereatti, 1993; Wagner and Houlihan, 1994). SS subscales also showed significant differences. Drag racers in comparison to archers were significantly higher on TAS subscale. According to Zuckerman (2004) TAS is the only subscale on which high and low-risk sport participants should differ due to the overall SS score which is a combination of all the subscales. The need for thrill and adventure was highlighted as the primary reason for participation in high-risk sports in more recent research (Kopp et al., 2016).

The present study also found significant differences between the drag racers and archers on the subscale of DIS. Drag racers scored higher than archers. DIS identifies a desire to engage in activities that go against society such as substance abuse, addictive gambling, or wild parties. According to Straub (1982) most athletes lead conforming lifestyles and DIS is not usually a discriminating measure of SS for people in sport. It must, however, be noted that limited research has been carried out with regards to SS subscale of DIS with extreme sport athletes, and further research in other extreme sports is needed to complement the present findings.

In view of differences in age between the drag racers and archers age, was used as a covariate in the analysis, however, it should be noted that according to Zuckerman (2004) SS increases with age into adolescence and then decreases throughout adulthood as adults prioritise other factors, such as decrease their desire for risk-taking activities and prioritising family activities (Kish and Donnenwerth, 1969; Zuckerman, 2004). SS is therefore expected to negatively correlate with age post adolescence. Zuckerman et al. (1978) also reported significant decreases in SS behaviour amongst the general public (age range from 16 to 70 years old) in his study in United Kingdom and in the United States. There were also age related decreases on TAS, the DIS and on the total SS results (Zuckerman et al., 1978).

\section{Limitations of the present findings}

In summary, the findings herein are not without certain limitations. As with all personality measures there could be a bias as to the extent to which participants may express their feelings. For example, participants may exaggerate the extent of their thrill seeking. The 'yes and no' nature of the response may also force the respondents to make a choice even if they felt slightly unsure, furthermore collecting qualitative data on participants could have been a valuable source of information and this was not gathered due to the extent to which professional athletes are willing to participate in research due to time constraints. Indeed, what has been achieved under the present conditions was largely due to the first author being a former professional drag racer, thus having access to this unique group of participants.

There is also a growing interest in extreme sport whereby particular events are showcased via their own dedicated TV channel; moreover the marketing of extreme experiences by commercial organisations such as 'Red Letter Days' and the 'Virgin Experience' has made 'extreme' activities more accessible to the public. This new familiarity of extreme experiences may necessitate further research as it may be the case that not all high risk or extreme sport participants are the same in terms of their personality profiles (Barlow et al., 2013). For example, Monasterio et al. (2014) identified differences between Alpinists and Rock climbers in their personality traits, although these two activities on the face of it would appear to be of similar risk. 


\section{Conclusion, Implications, and future research}

The main finding of the present study was that SS and its subscales are key distinguishing personality traits between two sports on differing ends of the extreme sport continuum. As commented by Goma-i-freixanet et al. (2012) there is a need for “...a useful tool to assess and interpret individual differences in personality traits that exist between sportspersons participating in sport with different levels of risk." Limited research suggests that individuals with high SS tend to exhibit active coping strategies during rehabilitation (Meredith et al., 2015) but ignore medical advice and continue with potentially destructive behaviour post rehabilitation (Pain and Kerr, 2004).

The fact that sport injuries are higher in extreme sports (Laver et al., 2017) and considering the present findings whereby Drag racers score higher on SS compared to Archers, it has implications for two growing bodies of research, (a) the significance of the need for psychological intervention in sport injury during and postsport rehabilitation (Schwab-Reese et al., 2012) and (b) the extent to which personality traits differ between different sports and play an integral role in the psychological models of rehabilitation and predicted outcomes (Pain and Kerr, 2004).

The immediate issue, however, is to examine the process of rehabilitation between individuals representing sports ranked high on the extreme sport continuum (for example drag racing and parachute jumping) and to find out if they would exhibit similar coping strategies during and post rehabilitation process or should a sport specific factor be added to the psychological models of sport injury rehabilitation?

\section{CONFLICT OF INTEREST}

No potential conflict of interest relevant to this article was reported.

\section{REFERENCES}

Allen MS, Greenlees I, Jones MV. Personality in sport: a comprehensive review. Int Rev Sport Exerc Psychol 2013;6:184-208.

Allen MS, Laborde S. The role of personality in sport and physical activity. Curr Dir Psychol Sci 2014;23:460-465.

Anshel MH, Lidor R. Talent detection programs in sport: the questionable use of psychological measures. J Sport Behav 2014;35:239-266.

Barlow M, Woodman T, Hardy L. Great expectations: different high-risk activities satisfy different motives. J Pers Soc Psychol 2013;105:458-475.

Bauger L, Eismann M, Vangberg HC. Personality traits among junior ath- letes in Norway, and a comparison with their non-athletic counterparts. Athl Insight: Online J Sport Psychol 2013;15:145-172.

Bullock WA, Gilliland K. Eysenck's arousal theory of introversion-extraversion: a converging measures investigation. J Pers Soc Psychol 1993; 64:113-123.

Butković A, Bratko D. Generation and sex differences in sensation seeking: results of the family study. Percept Mot Skills 2003;97(3 Pt 1):965970.

Chapman BP, Duberstein PR, Sörensen S, Lyness JM. Gender differences in five factor model personality traits in an elderly cohort: extension of robust and surprising findings to an older generation. Pers Individ Dif 2007:43:1594-1603.

Chirivella EC, Martínez LM. The sensation of risk and motivational tendencies in sport: an empirical study. Personal Individ Differ 1994;16: 777-786.

Cleary TJ, Zimmerman BJ. Self-regulation differences during athletic practice by experts, non-experts, and novices. J Appl Soc Psychol 2001;13: 185-206.

Cohen R, Baluch B, Duffy LJ. Defining extreme sport: conceptions and misconceptions. Front. Psychol 2018;9:1974. https://doi.org/10.3389/ fpsyg.2018.01974.

Cooper ML, Wood PK, Orcutt HK, Albino A. Personality and the predisposition to engage in risky or problem behaviors during adolescence. J Pers Soc Psychol 2003;84:390-410.

Duffy LJ, Baluch B. Ericsson KA. Dart performance as a function of facets of practice amongst professional and amateur men and women players. Int J Sport Psychol 2004;35:232-245.

Eagleton JR, McKelvie SJ, de Man A. Extraversion and neuroticism in team sport participants, individual sport participants, and nonparticipants. Percept Mot Skills 2007;105:265-275.

Egloff B. Gruhn AJ. Personality and endurance sports. Persnal Individ Differ 1996;21:223-229.

Eysenck HJ, Nias DK, Cox DN. Sport and personality. Adv Behav Res Ther 1982;4:1-56.

Eysenck SB, Eysenck HJ. Impulsiveness and venturesomeness: their position in a dimensional system of personality description. Psychol Rep 1978;43(3 Pt 2):1247-1255.

Eysenck SB, Eysenck HJ, Barrett P. A revised version of the psychoticism scale. Pers Individ Differ 1985;6:21-29

Garland DJ, Barry JR. Cognitive advantage in sport: the nature of perceptual structures. Am J Psychol 1991;104:211-228.

Goma-i-Freixanet M, Martha C, Muro A. Does the Sensation-Seeking trait differ among participants engaged in sports with different levels of physical risk? Ann Psychol 2012;28:223-232.

Guszkowska M, Bołdak A. Sensation seeking in males involved in recre- 
ational high risk sports. Biol Sport 2010;27:157-162.

Harris CR, Jenkins M, Glaser D. Gender differences in risk assessment: why do women take fewer risks than men? Judgm Decis Mak 2006;1: 48-63.

Immonen T, Brymer E, Davids K, Liukkonen J, Jaakkola T. An ecological conceptualization of extreme sports. Front Psychol 2018;9:1274.

Jack SJ, Ronan KR. Sensation seeking among high- and low-risk sports participants. Pers Individ Differ 1998;25:1063-1083.

Kajtna T, Tušak M, Barić R, Burnik S. Personality in high-risk sports athletes. Kinesiology 2004;36:24-34.

Kerr JH. Arousal-seeking in risk sports participants. Pers Individ Differ 1991;12:613-616.

Kish GB, Donnenwerth GV. Interests and stimulus seeking. J Couns Psychol 1969;16:551-556.

Kopp M, Wolf M, Ruedl G, Burtscher M. Differences in sensation seeking between alpine skiers, snowboarders and ski tourers. J Sports Sci Med 2016;15:11-16.

Larkin JE, Pines HA. Gender and risk in public performance. Sex Roles 2003;49:197-210.

Laver L, Pengas IP, Mei-Dan O. Injuries in extreme sports. J Orthop Surg Res 2017;12:59.

Martin CA, Kelly TH, Rayens MK, Brogli BR, Brenzel A, Smith WJ, Omar HA. Sensation seeking, puberty, and nicotine, alcohol, and marijuana use in adolescence. J Am Acad Child Adolesc Psychiatry 2002;41:14951502.

Meredith PJ, Rappel G, Strong J, Bailey KJ. Sensory sensitivity and strategies for coping with pain. Am J Occup Ther 2015;69:6904240010.

Monasterio E, Alamri YA, Mei-Dan O. Personality characteristics in a population of mountain climbers. Wilderness Environ Med 2014;25:214219.

Pain M, Kerr JH. Extreme risk taker who wants to continue taking part in high risk sports after serious injury. Br J Sports Med 2004;38:337-339.

Potgieter J, Bisschoff F. Sensation seeking among medium and low-risk sports participants. Percept Mot Skills 1990;71:1203-1211.

Rhodes RE, Smith NE. Personality correlates of physical activity: a review and meta-analysis. Br J Sports Med 2006;40:958-965.

Rossi B, Cereatti L. The sensation seeking in mountain athletes as assessed by Zuckerman's Sensation Seeking Scale. Int J Sport Psychol 1993;24: 417-431.

Ruedl G, Burtscher M, Wolf M, Ledochowski L, Bauer R, Benedetto KP, Kopp M. Are self-reported risk-taking behavior and helmet use associated with injury causes among skiers and snowboarders? Scand J Med Sci Sports 2015;25:125-130.

Schneider TA, Butryn TM, Furst DM, Masucci MA. A qualitative examination of risk among elite adventure racers. J Sport Behav 2007;30: 330-357.

Schwab-Reese LM, Pittsinger R, Yang J. Effectiveness of psychological intervention following sport injury. J Sport Health Sci 2012;1:71-79.

Slimani M, Bragazzi NL, Znazen H, Paravlic A, Azaiez F, Tod D. Psychosocial predictors and psychological prevention of soccer injuries: a systematic review and meta-analysis of the literature. Phys Ther Sport 2018;32:293-300.

Straub WF. Sensation seeking among high and low-risk male athletes. Human Kinet J 1982;4:246-253.

VanZile-Tamsen C, Testa M, Harlow LL, Livingston JA. A measurement model of women's behavioral risk taking. Health Psychol 2006;25:249254.

Wagner AM. Houlihan DD. Sensation seeking and trait anxiety in hangglider pilots and golfers. Persnal Individ Differ 1994;16:975-977.

Watson AE, Pulford BD. Personality differences in high risk sports amateurs and instructors. Percept Mot Skills 2004;99:83-94.

Zuckerman M. Sensation seeking and risky behaviour. Washington, DC: American Psychological Association; 2007.

Zuckerman M. The psychophysiology of sensation seeking. J Pers 1990; 58:313-345.

Zuckerman M. The shaping of personality: genes, environments, and chance encounters. J Pers Assess 2004;82:11-22.

Zuckerman M, Eysenck S, Eysenck HJ. Sensation seeking in England and America: cross-cultural, age, and sex comparisons. J Consult Clin Psychol 1978;46:139-149. 